\title{
Desenvolvimento de buttermilk probiótico
}

\author{
Development of a probiotic buttermilk
}

\author{
Adriane Elisabete Costa ANTUNES ${ }^{1}$, Elza Terezinha Grael MARASCA ${ }^{1 *}$, Izildinha MORENO ${ }^{1}$, \\ Fernanda Martelo DOURADO ${ }^{1}$, Luana Gajardoni RODRIGUES ${ }^{1}$, Alda Luiza Santos LERAYER ${ }^{1}$
}

\begin{abstract}
Resumo
Atualmente, são lançados no mercado diversos novos produtos, sendo que na área de laticínios a ênfase é para os funcionais. Esta pesquisa propõe o desenvolvimento de uma bebida láctea fermentada, denominada buttermilk, que seja probiótica, apresente opções de sabor, que tenha versões dietéticas e que atenda à legislação brasileira. A primeira etapa do trabalho consistiu na determinação do fluxograma de preparo do produto para determinar os melhores momentos para adição de sacarose, sucralose e da cultura probiótica. Na etapa seguinte, foi avaliada a qualidade microbiológica de corantes e aromatizantes para empregá-los, sem tratamento térmico, no produto fermentado. Posteriormente, foram analisadas as amostras de buttermilk de diversos sabores, durante o armazenamento, para verificar se a adição de sacarose, edulcorante, aromatizantes e corantes interferiria nas contagens microbiológicas. Os resultados indicaram que a adição da cultura probiótica deve ser feita pré-fermentação e que corantes e aromatizantes podem ser adicionados no produto já fermentado. Observou-se que as amostras de buttermilk com sacarose adicionadas de agentes de cor e aromatizantes tenderam a apresentar menores contagens de bifidobactérias após a estocagem. Porém, todos os sabores de buttermilk se mantiveram adequados à legislação quanto aos aspectos de higiene e de número de bifidobactérias. B. animalis subsp. lactis apresentou excelente viabilidade durante o armazenamento do produto (média de $1,3.10^{8}$ UFC. $\mathrm{mL}^{-1}$ ). As amostras de buttermilk podem, assim, ser consideradas seguras para consumo, além de potencialmente funcionais. Palavras-chave: buttermilk; probiótico; viabilidade; aspectos higiênico-sanitários.
\end{abstract}

\begin{abstract}
New food products are launched on the market nearly every day and the main focus of the dairy industry is on functional products. The aim of this research project is to develop a fermented probiotic dairy product - buttermilk -, in a variety of flavors - including diet versions - in compliance with Brazilian regulations. As a first step, the manufacturing process of buttermilk was tested and evaluated to determine the best method and process step to add sucrose, sucralose and the probiotic culture. The next step consisted of evaluating the microbiological quality of coloring agents and flavor compounds intended to be added - without prior heat treatment - to the fermented product. In the next stage of the project, buttermilk samples of different flavors were analyzed during cold storage to observe whether sugar, sweetener, flavor compounds and coloring agents would interfere with microbiological counts. The results obtained at the end of the storage period indicated that the probiotic culture should be added prior to fermentation, while flavor compounds and coloring agents could be added directly to the fermented product after completing the culturing process. It was observed that the buttermilk samples containing sucrose and added with flavor compounds and coloring agents tended to show lower bifidobacterial counts after storage. Nevertheless, all the flavor versions of buttermilk tested met the legal requirements regarding hygiene indicators and the number of viable probiotic bacteria. B. animalis subsp. lactis showed excellent viability exhibiting an average count of $1.3 .10^{8} \mathrm{cfu} . \mathrm{mL}^{-1}$. As a result, the buttermilk samples were considered safe and potentially functional.
\end{abstract}

Keywords: buttermilk; probiotic; viability; hygiene.

\section{Introdução}

Uma nova tendência da indústria de alimentos é a produção de iogurtes e leites fermentados funcionais. Isto porque, além destes produtos possuírem grande aceitação pelo público em geral e apresentarem excelente valor nutritivo, são veículos em potencial para o consumo de probióticos. Segundo HELLER ${ }^{13}$, os consumidores estão familiarizados com o fato de que alimentos fermentados podem apresentar microrganismos vivos.

Os probióticos são definidos como adjuntos dietéticos microbianos que afetam beneficamente a fisiologia do hospedeiro pela regulação da imunidade local e sistêmica e pela melhora do balanço nutricional e microbiano do trato intestinal ${ }^{17}$.

Apenas iogurtes e leites fermentados contendo culturas probióticas devem ser considerados funcionais ${ }^{1}$. No entanto, os consumidores em geral não sabem distinguir quais são os

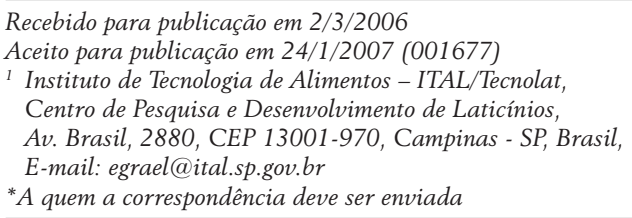

produtos lácteos funcionais. A própria legislação brasileira para alimentos funcionais é incipiente.

Uma questão ainda não conclusa pela literatura é a quantidade e freqüência de consumo de probióticos necessários para assegurar os benefícios funcionais a eles atribuídos ${ }^{10}$. Preconiza-se ingestão semanal mínima de 300 a 500 g de produtos lácteos fermentados contendo entre $10^{6}$ a $10^{7}$ UFC.mL ${ }^{-1}$, ou seja, entre 1 milhão e 10 milhões das células probióticas por mililitro de produto ${ }^{21,23}$. As embalagens de leites fermentados comercializados no Brasil apresentam geralmente $80 \mathrm{~mL}$ de produto e, segundo SAXELIN, KORPELA e MAYARA-MAKINEN ${ }^{20}$, essas garrafas pequenas fazem parte do conceito de "dose diária" de companhias multinacionais. A ingestão diária de leites fermentados embalados em garrafas de $80 \mathrm{~mL}$ totaliza consumo semanal de $560 \mathrm{~mL}$. É preciso, no entanto, que estes produtos tenham sido fabricados adequadamente e estocados na temperatura de refrigeração correta para de fato apresentarem quantidade alta de microrganismos probióticos viáveis.

No Brasil, dos diversos leites fermentados disponíveis no mercado, apenas alguns contêm no rótulo a identificação do 
microrganismo presente. Em geral, o fabricante limita-se a informar que o produto contém "fermentos lácteos". No entanto, a linhagem de microrganismo presente no produto, bem como o número de células viáveis desta cultura, é que determina se este é ou não funcional. A legislação deveria exigir que fosse veiculada essa informação no rótulo para assim permitir aos consumidores a escolha de produtos com linhagens potencialmente benéficas à saúde. Além disso, sem estas informações do fabricante, é impossível o controle de qualidade pelas agências governamentais de fiscalização.

Dois estudos foram feitos recentemente, avaliando os iogurtes e leites fermentados comercializados no mercado brasileiro. O primeiro teve como objetivo verificar a contagem de Lactobacillus acidophilus e bifidobactérias viáveis em produtos que declaravam a presença destes microrganismos, sendo obtidas contagens abaixo de $10^{5} \mathrm{UFC} \cdot \mathrm{mL}^{-1}$, em grande parte das amostras analisadas ${ }^{5}$. O outro estudo observou que nem todas as espécies declaradas nos rótulos eram encontradas nos produtos (particularmente L. acidophilus e B. bifidum), que várias espécies declaradas não estavam presentes, e que a nomenclatura de algumas espécies estava ultrapassada em alguns $\operatorname{casos}^{6}$. Produtos encontrados no mercado internacional também apresentam rotulagem não conforme com o microrganismo presente no produto, bem como quantidades baixas de células viáveis das culturas presentes ${ }^{24}$.

O buttermilk é uma bebida láctea fermentada, apreciada em diversos países como Alemanha, Bélgica, Holanda, Dinamarca e Estados Unidos. Freqüentemente, na região norte da Europa e nos Estados Unidos, o buttermilk é consumido como uma bebida refrescante, com cereais ou como substituto do leite fresco ${ }^{14}$. Por ser produzido originalmente a partir do leitelho, obtido na fabricação de manteiga, agrega valor a este subproduto. A adição de culturas probióticas ao buttermilk proporcionaria uma nova opção no mercado de bebida fermentada com alegação de promover saúde.

A indústria de laticínios tem grande interesse no buttermilk devido ao seu delicado sabor, bem como ao seu alto valor nutricional ${ }^{12}$. Segundo O'CONNELL e FOX ${ }^{18}$, a produção mundial de buttermilk é de $6,5 \times 10^{6}$ toneladas anuais. O buttermilk é, portanto, um importante candidato à conquista de nicho de mercado, especialmente se adicionado de cultura probiótica, pois, além da alegação de promover saúde, é extremamente aromático e apresenta sabor refrescante, sendo, segundo $\mathrm{BROLAZO}^{8}$, apropriado para o clima tropical do Brasil.

RODAS et al. ${ }^{19}$ elaboraram formulação de buttermilk probiótico, obtendo contagens acima de $10^{6}$ UFC.mL $L^{-1}$ de L. reuteri por até 10 dias de estocagem refrigerada, utilizando $1 \%$ deste microrganismo como inóculo no início da fermentação.

Bifidobacterium animalis subps. lactis, anteriormente classificada como Bifidobacterium lactis $^{15}$, foi escolhido para esta pesquisa por ser empregado industrialmente como probiótico em iogurtes, leites fermentados, queijos, bebidas, molhos, suplementos dietéticos, fórmulas infantis e cereais há mais de dez $\operatorname{anos}^{16,25}$.

Esta pesquisa teve por objetivo desenvolver um novo produto para o mercado brasileiro de laticínios com diversas opções de sabores, que tenha versões dietéticas dos sabores, que seja probiótico, e que atenda à legislação em vigor.

\section{Material e métodos}

\subsection{Material}

\section{Culturas microbianas}

Foram utilizadas culturas comerciais liofilizadas de Bifidobacterium animalis subsp. lactis (BB12, Madri/Espanha) e Mesophilic Aromatic Culture (MAC CHN-22, Horsholm/ Dinamarca), composta por mistura de linhagens contendo Lactococcus lactis subsp. cremoris, Lactococcus lactis subsp. lactis, Lactococcus lactis subsp. lactis biovar. diacetylactis e Leuconostoc mesentoroides subsp. cremoris, ambas cedidas pela Christian Hansen.

\subsection{Métodos}

\section{Preparo dos inóculos}

As culturas liofilizadas em pó de B. animalis subsp. lactis BB12 e MAC “(Mesophilic Aromatic Culture, composta pelos microrganismos acima citados) foram suspensas em $1 \mathrm{~L} \mathrm{e} 2 \mathrm{~L}$, respectivamente, de leite tipo A integral estéril e aliquotadas em porções correspondentes ao volume necessário para fermentar $1 \mathrm{~L}$ de leite. Visto que a cultura probiótica seria inoculada a $2 \%$, foi fracionada em tubos estéreis na quantidade de $20 \mathrm{~mL}$. A cultura MAC, cuja inoculação seria a 1\%, foi fracionada no volume de $10 \mathrm{~mL}$. Os inóculos foram estocados a $-20^{\circ} \mathrm{C}$.

\section{Preparo do buttermilk}

No preparo de buttermilk com açúcar ou dietético, nos sabores natural, morango, baunilha, abacaxi com menta, graviola e cupuaçu, empregaram-se: leite desnatado UHT (adquirido no comércio local), sacarose (adquirida no comércio local), sucralose (da marca Taste \& Lyle Sucralose, cedida pela empresa Tovani Benzaquen Rep. Ltda.), aromatizantes e corantes (recebidos por doação de diferentes empresas brasileiras ou filiadas no Brasil). As marcas e quantidades de aromas e corantes utilizados estão descritas na Tabela 1. Para o sabor baunilha, foi empregada uma combinação de corantes. Os sabores cupuaçu e graviola não foram adicionados de agentes de cor.

O leite UHT, no volume de $500 \mathrm{~mL}$, foi acondicionado em garrafas Schott de $1 \mathrm{~L}$, adicionado de sacarose (10\% $\left.\mathrm{m} . \mathrm{v}^{-1}\right)$ ou sucralose $\left(0,03 \% \mathrm{~m} . \mathrm{v}^{-1}\right)$, aromatizantes e corantes, em dois momentos diferentes. Seguiu-se a pasteurização lenta $\left(65 \pm 1{ }^{\circ} \mathrm{C}\right.$ por 30 minutes), resfriamento até temperatura ambiente, inoculação com $1 \%\left(\mathrm{v}^{-1} \mathrm{v}^{-1}\right)$ de MAC e de $2 \%$, pré e pós-fermentação (ver procedimento experimental), de cultura probiótica $\left(v \cdot \mathrm{v}^{1}\right) \mathrm{e}$ posterior incubação a $21 \pm 1{ }^{\circ} \mathrm{C}$ de 15 a 20 horas, até as amostras atingirem $\mathrm{pH} 5,0 \pm 0,1$. O monitoramento do $\mathrm{pH}$ foi feito com o uso de potenciômetro digital. Ao atingirem o pH fixado, as amostras foram homogeneizadas manualmente por agitação das garrafas e imediatamente refrigeradas $\left(6{ }^{\circ} \mathrm{C} \pm 2\right)$. 
Tabela 1. Aromas e corantes empregados para produção de $100 \mathrm{~mL}$ de buttermilk de diversos sabores.

\begin{tabular}{|c|c|c|c|c|c|}
\hline \multirow[t]{2}{*}{ Sabor } & \multicolumn{2}{|c|}{ Aromatizante } & \multicolumn{3}{|c|}{ Corante } \\
\hline & Marca & Quantidade $(\mu \mathrm{L})$ & Marca & Cor & Quantidade $(\mu \mathrm{L})$ \\
\hline Morango & Symrise & 50 & Corantec & Carmim & 12 \\
\hline Baunilha & Symrise & 150 & EPA** e Corantec $^{* *}$ & Caramelo e Amarelo & 40 e 10 \\
\hline Abacaxi* & Proaroma & 40 & Corantec & Amarelo & 20 \\
\hline Menta* & Proaroma & 40 & & & \\
\hline Cupuaçu & Duas Rodas & 50 & - & - & - \\
\hline Graviola & Symrise & 80 & - & - & - \\
\hline
\end{tabular}

Qualidade higiênico-sanitária dos

ingredientes e dos produtos

Os aromas e corantes foram analisados microbiologicamente para verificar a sua possibilidade de aplicação no produto já pasteurizado e fermentado.

Amostras de buttermilk de todos os sabores, nas versões dietética e com adição de sacarose, foram analisadas por parâmetros de higiene no primeiro e último dia $\left(28^{\circ}\right)$ de armazenamento refrigerado $\left(6^{\circ} \mathrm{C} \pm 2\right)$.

\section{Determinação de coliformes}

Os meios de cultura Caldo Lauril Sulfato Triptose (LST) e Caldo Lactosado com Bile e Verde Brilhante (CLBVB) foram utilizados para a determinação de Coliformes Totais. Coliformes fecais foram identificados empregado-se Caldo Laurilsulfato (LST com Mug). Os resultados obtidos foram expressos em NMP.mL ${ }^{-1}$ (número mais provável por mililitro). A metodologia para estas contagens está descrita em SILVA, JUNQUEIRA e SILVEIRA ${ }^{22}$.

\section{Determinação de bolores e leveduras}

Bolores e leveduras foram determinados por meio de plaqueamento das amostras em superfície em Ágar Dicloran Rosa de Bengala Cloranfenicol (DRBC), com incubação por 5 dias a $25{ }^{\circ} \mathrm{C}$. O resultado foi expresso em UFC.mL ${ }^{-1}$ (unidade formadora de colônias por mililitro) segundo SILVA, JUNQUEIRA e SILVEIRA ${ }^{22}$.

\section{Procedimento experimental}

A Figura 1 apresenta o fluxograma de preparo do buttermilk. Duas variáveis foram avaliadas: a etapa da adição de sacarose ou sucralose (antes da pasteurização ou após a fermentação) e a etapa da adição da cultura probiótica (pré ou pós-fermentação). As quatro possibilidades de fluxograma correspondem às combinações descritas na Tabela 2 .

Tabela 2. Processamentos e correspondentes às etapas da adição de sacarose ou sucralose e de cultura probiótica.

\begin{tabular}{cll}
\hline Processamentos & $\begin{array}{c}\text { Adição de sacarose } \\
\text { ou sucralose }\end{array}$ & $\begin{array}{c}\text { Adição de B. animalis } \\
\text { subsp. lactis }\end{array}$ \\
\hline 13 & antes da pasteurização & antes da fermentação \\
14 & antes da pasteurização & após a fermentação \\
23 & após fermentação & antes da fermentação \\
24 & após fermentação & após a fermentação \\
\hline
\end{tabular}

Viabilidade das culturas no buttermilk

A viabilidade das culturas mesofílicas e da probiótica nas amostras foi feita no produto fresco ( $1^{\circ}$ dia) e no final do armazenamento ( $\left.28^{\circ} \mathrm{dia}\right)$, determinando-se o número de células viáveis pelo método de semeadura em profundidade.

\section{Contagem de culturas mesofílicas aromáticas}

Empregou-se meio NICKELS e LESSMENT, modificado por VOGENSEN et al. ${ }^{27}$. A incubação foi aeróbica a $25{ }^{\circ} \mathrm{C}$ por 72 horas e, depois de adicionado $0,5 \mathrm{~mL}$ de solução de $\mathrm{X}$-Gal (5-bromo-4-chloro- $\beta$-D-galactopyranoside) às placas, seguiu-se a incubação por mais 24 horas. Foram feitas duplicatas dos cultivos e as médias dos resultados foram expressas como $\log _{10}$ UFC.mL ${ }^{-1}$. Colônias azuis identificam Leuconostoc mesentoroides subsp. cremoris, colônias brancas com produção de halo identificam Lactococcus lactis subsp. lactis biovar. diacetylactis e colônias brancas sem halo identificam $L$. lactis subps. lactis ou cremoris ${ }^{27}$. Visto que o meio não permite a diferenciação das colônias de Lac. lactis subsp. cremoris e subsp. Lactis, estas culturas foram enumeradas juntas.

\section{Contagem de B. animalis subps. lactis BB12}

O meio de cultivo MRS ágar suplementado ${ }^{9}$ também permite o crescimento de culturas MAC, conforme verificado previamente por este grupo de pesquisa ${ }^{3}$. Portanto, este meio foi modificado para alcançar seletividade para B. animalis subps. lactis. Os reagentes para preparo de $100 \mathrm{~mL}$ deste meio são: $7 \mathrm{~g}$ de MRS ágar, 0,5 mL de solução de L-cisteína HCL a 10\%, $1 \mathrm{~mL}$ de solução de cloreto de lítio a $10 \%$ e $0,02 \mathrm{~g}$ de azul de anilina. A incubação foi anaeróbica utilizando-se gás gerador de anarobiose (Anaerogen, Oxoid / Inglaterra) por 72 horas. As contagens foram feitas em duplicatas e os resultados expressos como $\log _{10}$ UFC.mL ${ }^{-1}$. A concentração de corante foi aumentada para melhor evidenciar as colônias, a temperatura de incubação passou de 37 para $45{ }^{\circ} \mathrm{C}$ para inibir as culturas mesofílicas, enquanto que a dicloxacilina (antibiótico originalmente utilizado para inibir Streptococcus) não foi adicionada ${ }^{3}$.

\section{Análise estatística}

Os resultados médios das contagens microbiológicas das culturas MAC e de bifidobactérias, expressos como $\log _{10}$ UFC.mL $\mathrm{mL}^{-1}$, foram analisados por Tukey $(\mathrm{p}<0,05)$ para a comparação das médias com o programa SAS (v.8.2, 2001). 


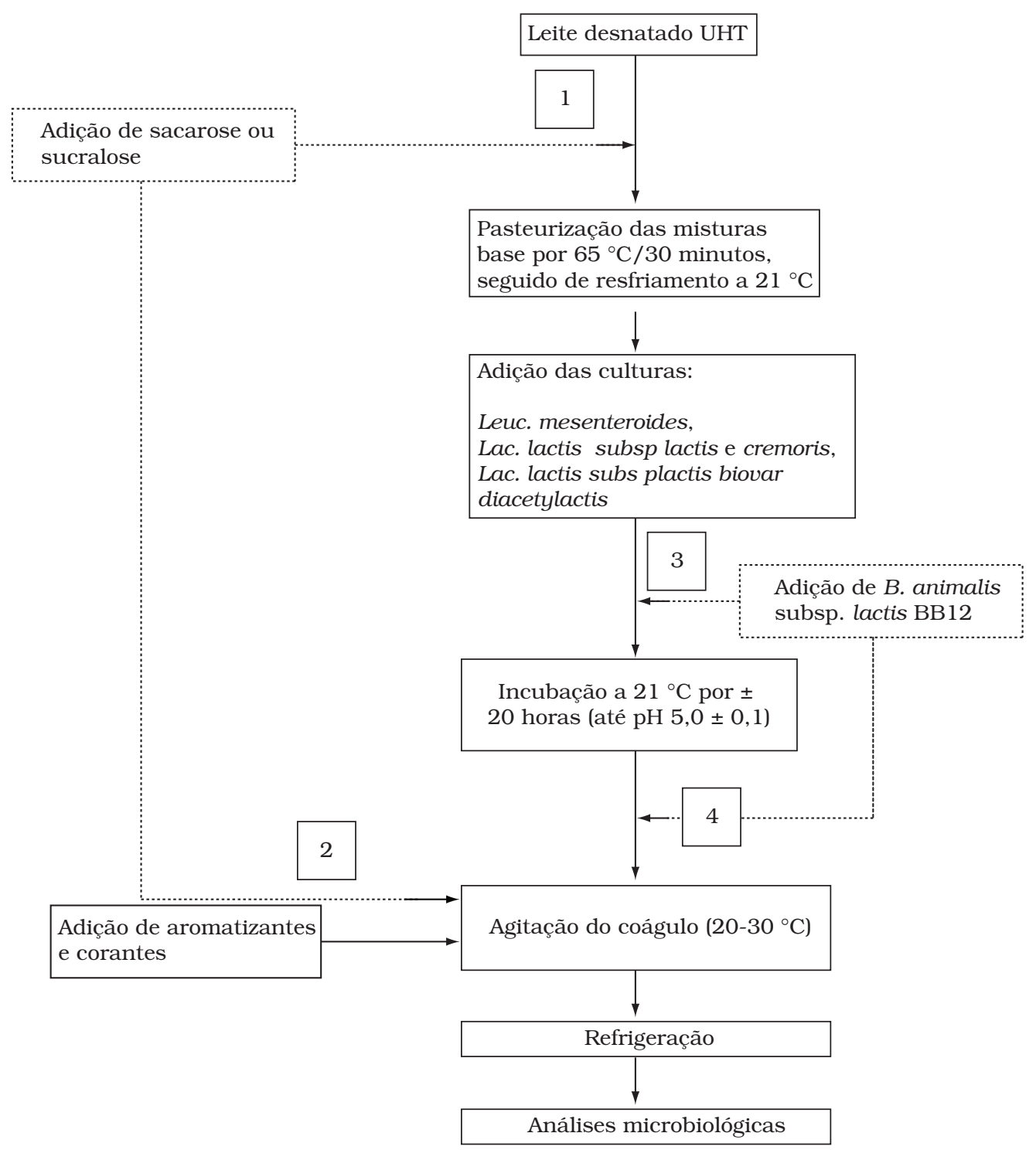

Figura 1. Fluxograma de produção do buttermilk. 1) adição de sacarose ou sucralose antes da pasteurização; 2) adição de sacarose ou sucralose após a fermentação; 3) adição de B. animalis subp. lactis antes da fermentação; e 4) adição de B. animalis subp. lactis após a fermentação.

\section{Resultados e discussão}

\subsection{Qualidade higiênico-sanitária dos ingredientes}

Os aromas e corantes selecionados nas formulações de buttermilk foram analisados por indicadores de qualidade higiênico-sanitárias. Estes ingredientes costumam ser adicionados no final do processamento porque o tratamento térmico leva à perda de voláteis (prejudicando o aroma) e pode interferir na estabilidade da cor do produto.

Para todas as amostras, foram obtidos valores de coliformes totais e fecais $<3 \mathrm{NMP}^{-1}$ e de bolores e leveduras $<10$ UFC. $\mathrm{mL}^{-1}$. Portanto, a utilização destas marcas comerciais de ingredientes após a fermentação (sem sofrer tratamento térmico) foi considerada viável.

\subsection{Determinação do fluxograma de preparo do buttermilk}

Avaliaram-se amostras de buttermilk sabor natural com sacarose e sucralose, nas quatro possibilidades de processamento, seguindo-se análises de coliformes, bolores e leveduras e B. animalis subsp. lactis, conforme Tabela 3 .

O Ministério de Agricultura, Pecuária e Abastecimento estabelece Padrões de Qualidade e Identidade (PIQ) para leites fermentados, porém, para o buttermilk não existem especificações, visto ser um produto ainda não comercializado no Brasil ${ }^{7}$. Segundo esta resolução, os critérios microbiológicos aceitáveis para uma amostra de leite fermentado são: contagens máximas de $100 \mathrm{NMP}^{\mathrm{mL}} \mathrm{L}^{-1}$ para coliformes totais, $10 \mathrm{NMP}^{-1} \mathrm{LL}^{-1}$ para coliformes fecais, 200 UFC. $\mathrm{mL}^{-1}$ para bolores e leveduras. 
Tabela 3. Análises microbiológicas de buttermilk natural preparado por diferentes processamentos e adequação com a legislação.

\begin{tabular}{|c|c|c|c|c|c|}
\hline \multirow[t]{2}{*}{ Processamento } & \multirow[t]{2}{*}{ B. lactis $\log _{10}$ UFC.mL $\mathrm{mL}^{-1}$} & \multicolumn{2}{|c|}{ Coliformes NMP.mL $L^{-1}$} & \multirow[t]{2}{*}{ Bolores e leveduras UFC.mL ${ }^{-1}$} & \multirow[t]{2}{*}{ Legislação } \\
\hline & & $\left(30^{\circ} \mathrm{C}\right)$ & $\left(45^{\circ} \mathrm{C}\right)$ & & \\
\hline 13 sacarose & $8,32 \pm 0,02^{\mathrm{a}}$ & $<3$ & $<3$ & $<10$ & $\mathrm{~V}$ \\
\hline 14 sacarose & $7,99 \pm 0,00^{\mathrm{b}, \mathrm{c}}$ & $<3$ & $<3$ & $<10$ & $\mathrm{~V}$ \\
\hline 23 sacarose & $7,97 \pm 0,01^{\mathrm{c}, \mathrm{d}}$ & $<3$ & $<3$ & $<10$ & $\mathrm{~V}$ \\
\hline 24 sacarose & $7,90 \pm 0,02^{\mathrm{d}}$ & $<3$ & $<3$ & $<10$ & $\mathrm{~V}$ \\
\hline 13 sucralose & $8,23 \pm 0,02^{\mathrm{a}, \mathrm{b}}$ & $<3$ & $<3$ & $<10$ & $\mathrm{~V}$ \\
\hline 14 sucralose & $8,07 \pm 0,08^{\mathrm{b}, \mathrm{c}}$ & $<3$ & $<3$ & $<10$ & $\mathrm{~V}$ \\
\hline 23 sucralose & $8,11 \pm 0,02^{b}$ & $<3$ & $<3$ & $<10$ & $\mathrm{~V}$ \\
\hline 24 sucralose & $7,98 \pm 0,00^{\mathrm{c}, \mathrm{d}}$ & $<3$ & $<3$ & $<10$ & $\mathrm{~V}$ \\
\hline
\end{tabular}

Médias \pm desvio padrão, seguidas pela mesma letra não diferiram estatisticamente ( $<<0,05)$; e V - está adequado à legislação.

Um parâmetro importante nesta avaliação era verificar qual o momento (pré ou pós-fermentação) da adição de B. animalis subsp. lactis resultaria em números mais elevados desta cultura. Os resultados indicaram que a adição da linhagem BB12 na pré-fermentação do produto levou a valores similares ou mais elevados, em alguns casos diferindo estatisticamente $(\mathrm{p}<0,05)$ da amostra cuja adição de BB12 ocorreu no final da fermentação (Tabela 3). Este dado está em consonância com RODAS et al. ${ }^{19}$, que obtiveram populações maiores da cultura probiótica com a qual trabalharam (L. reuteri), quando sua adição foi feita antes da fermentação do buttermilk elaborado a partir do leite desnatado. A viabilidade do L. reuteri decresceu em até 3 ciclos logarítmicos no buttermilk inoculado com a cultura probiótica após a fermentação. Segundo estes autores, quando a cultura probiótica era adicionada juntamente com os demais microrganismos do inóculo, ela tinha condições mais favoráveis para competir por nutrientes.

O tipo de agente de adoçamento não interferiu na viabilidade da B. animalis subps. lactis. Amostras processadas da mesma forma, porém adicionadas de sacarose ou sucralose (13 sacarose e 13 sucralose e assim, sucessivamente), não diferiram estatisticamente $(\mathrm{p}<0,05)$ nas contagens de bifidobactérias, com exceção do processamento 23 sacarose e 23 sucralose, que resultou em maior número de B. lactis na amostra adicionada de sucralose. Amostras com sacarose e sucralose apresentaram resultados muito semelhantes, ou seja, respectivamente, médias de 8,04 e 8,09 $\log _{10}$ UFC.mL ${ }^{-1}$ de bifidobactérias.

A etapa da adição de sacarose ou sucralose e da cultura probiótica não interferiram na qualidade higiênica das amostras. Acreditava-se que a adição de sacarose após a fermentação (processamentos 23 e 24) levaria à contaminação dos produtos, assim como observado em trabalho que precedeu a presente pesquisa $^{8}$. Visto ser a sacarose adicionada ao leite em uma quantidade representativa $\left(10 \% \mathrm{~m} . \mathrm{v}^{-1}\right)$ e poder representar risco de contaminação do produto, definiu-se que ela seria aplicada antes do tratamento térmico. Embora dispondo do laudo do fabricante de sucralose, contendo análises físico-químicas e microbiológicas que indicavam sua qualidade adequada, foi feita a opção por adicioná-la antes da pasteurização, assim como seria feito com a sacarose.

Através dos resultados obtidos fixou-se fluxograma de processamento do buttermilk da seguinte forma: adição de sacarose ou sucralose ao leite antes da pasteurização, adição de BB12 e MAC ao mesmo tempo (antes da incubação), e adição de agentes corantes e aromatizantes após a fermentação do produto.

\subsection{Qualidade higiênico-sanitária e viabilidade das culturas no buttermilk}

Definido o procedimento de preparo do buttermilk, foram fermentadas amostras de todos os sabores e feitas análises microbiológicas no início e final do armazenamento.

Conforme as Tabelas 4 e 5, observou-se que durante o armazenamento ocorreu alteração na população de culturas aromáticas mesofílicas. No primeiro dia de armazenamento das amostras, a população das culturas MAC apresentou-se balanceada. As contagens das culturas Leu. mesenteroides não apresentaram diferença estatisticamente significativa e o mesmo foi observado para Lac. lactis das subsp. lactis e cremoris. As contagens de Lac. lactis subsp. lactis biovar. diacetylactis apresentaram variações entre os tratamentos, com reduções de dois ciclos logarítmicos o que pode refletir em alterações no perfil de aroma do produto.

No início do armazenamento, a adição de edulcorante, corantes e aromatizantes não influenciou na população microbiana obtida. Ao término da estocagem, as amostras de todos os sabores adicionadas de sacarose, quando comparadas ao sabor natural, tenderam a apresentar populações de bifidobactérias estatisticamente mais baixas. Por outro lado, os sabores abacaxi com menta, graviola e cupuaçu dietéticos apresentaram populações maiores que as amostras dos mesmos sabores adicionadas de sacarose. VINDEROLA et al. ${ }^{26}$ avaliaram a influência de aditivos comumente empregados na indústria de laticínios no desenvolvimento de culturas lácteas e probióticas, tais como açúcares (sacarose e lactose), edulcorantes (aspartame e acessulfame), diversos agentes corantes e aromatizantes, entre outros, os quais foram adicionados diretamente ao meio de cultura. Alguns destes agentes (como adoçantes e aromatizantes), adicionados nas concentrações empregadas industrialmente, não influenciaram no desenvolvimento das culturas. Concentrações mais elevadas de alguns flavorizantes, entretanto, foram inibitórias para as culturas, especialmente as bactérias lácticas.

As bifidobactérias apresentaram excelente viabilidade durante todo o armazenamento do buttermilk. Comparando-se as contagens inicias e finais das populações de bifidobactérias, 

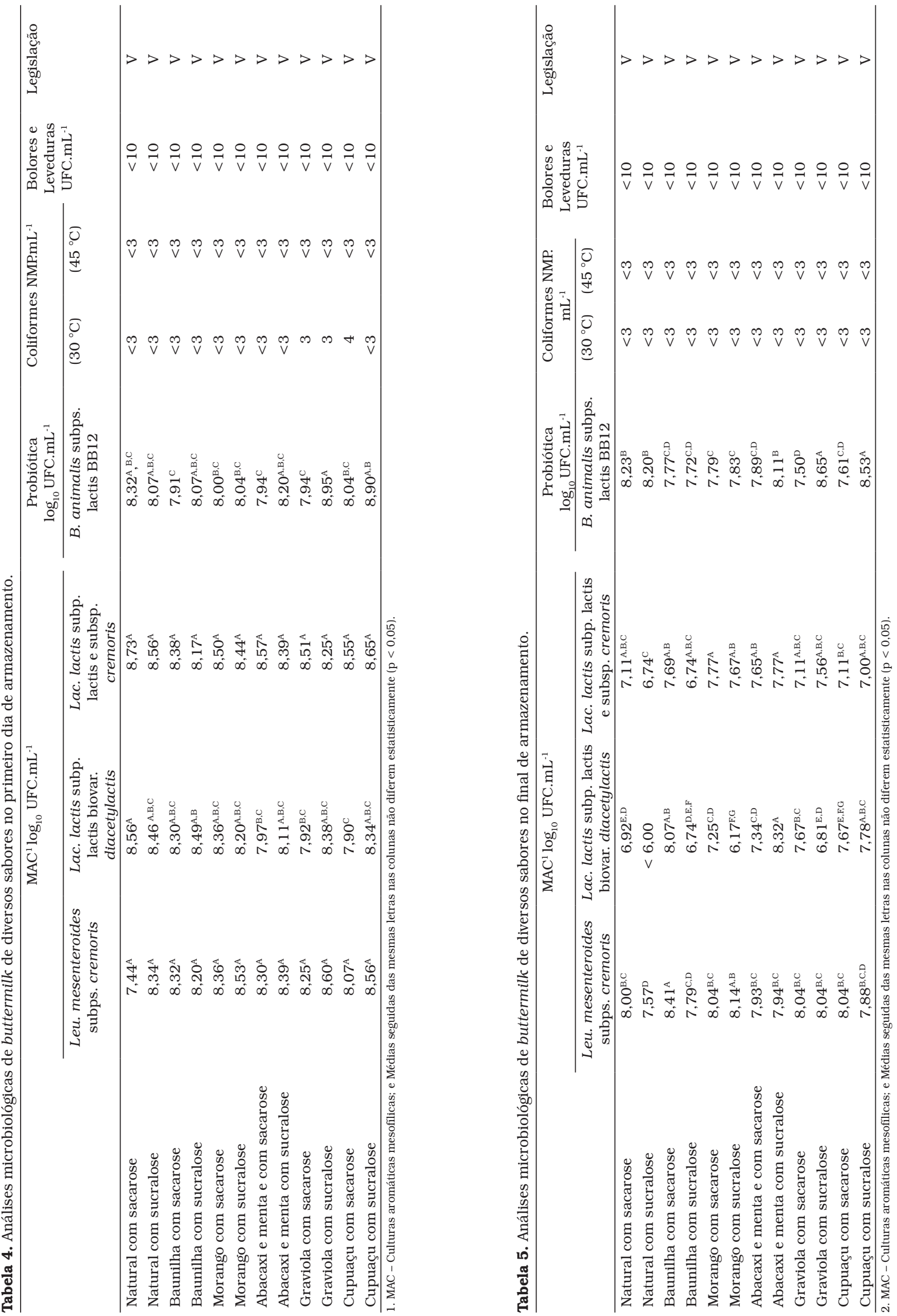
apenas os sabores graviola com sacarose, graviola com sucralose e cupuaçu com sacarose apresentaram diferença estatisticamente significativa ( $\mathrm{p}<0,05$ ), conforme explorado em trabalho anterior ${ }^{4}$. Segundo os Padrões de Qualidade e Identidade (PIQ) para leites fermentados, quando é mencionado no rótulo de um produto o uso de bifidobactérias, a população mínima desta cultura deverá ser de $10^{6}$ UFC por grama ou mililitro do produto. Todos os sabores tiveram contagens acima daquela estabelecida pela legislação nacional ${ }^{7}$. As bifidobactérias, em geral, são fastidiosas e apresentam baixa sobrevivência, especialmente quando presentes em alimentos ácidos, tais como iogurtes e leites fermentados. ANTUNES et al. ${ }^{2}$, desenvolvendo iogurtes naturais probióticos, observaram ao final do armazenamento, contagens de B. longum inferiores a $5 \log _{10} \mathrm{UFC} \cdot \mathrm{mL}^{-1}$.

A linhagem BB12, utilizada neste estudo, é tecnologicamente adequada para aplicação em buttermilk, uma vez que apresentou populações acima de $7,5 \log _{10}$ UFC.mL-1 e, conjuntamente, apresentou compatibilidade com a cultura MAC sem inibir ou ser inibida por esta. A literatura cita como vantagens tecnológicas do emprego desta linhagem em leites fermentados: boa viabilidade, compatibilidade com outras culturas lácticas e tolerância ao oxigênio (ainda que as bifidobactérias sejam reconhecidamente anaeróbias). Entre as qualidades funcionais da B. animalis subsp. lactis BB12, HASCHKE et al. ${ }^{11}$ citam excelente sobrevivência durante o trânsito intestinal e adesão aos enterócitos. Estas são condições essenciais para que uma cultura seja considerada probiótica.

No que se refere aos parâmetros de higiene, todas as amostras atenderam às exigências do Ministério da Agricultura, Pecuária e Abastecimento ${ }^{7}$. No buttermilk fresco dos sabores cupuaçu com sacarose, graviola com sacarose e com sucralose foram detectados Coliformes Totais, porém em número abaixo dos limites permitidos pela legislação. Nas análises subseqüentes, ao término do armazenamento, esses resultados não se repetiram. É possível que estes microrganismos tenham sido inibidos pelas demais culturas presentes no produto.

Um problema tecnológico observado nas amostras, todavia, foi a intensa dessoragem durante o armazenamento (cerca de $20 \%$ em relação ao volume do produto).

Este foi um trabalho preliminar, realizado em nível de bancada, que demonstrou a possibilidade de obtenção de um leite fermentado probiótico inexistente no mercado nacional. Outras variáveis serão posteriormente avaliadas, visando impedir a separação de fases do produto, tais como: diferentes tipos de matéria-prima (leite em pó e pasteurizado), emprego de gomas, variações no tratamento térmico e homogeneização mecânica do buttermilk.

\section{Conclusões}

A produção de buttermilk contendo B. animalis subsp. lactis é viável devido à compatibilidade de desenvolvimento desta cultura com as culturas aromáticas mesofílicas.

As contagens de B. animalis subsp. lactis tendem a ser mais elevadas nas amostras com adição desta cultura préfermentação, ou seja, quando a B. animalis subsp. lactis é adicionada conjuntamente à cultura MAC (Mesophilic Aromatic Culture), antes da incubação.

A adição de aromas e corantes ao buttermilk, observando boas práticas de fabricação, não representou risco de contaminação do produto, podendo ser feita no final do processamento. No entanto, estes ingredientes podem interferir nas populações das culturas durante o armazenamento do produto. Ainda assim, o número de células viáveis $B$. animalis subsp. lactis atendeu à legislação em todas as amostras.

As análises do buttermilk, de todos os sabores, ao término do armazenamento indicaram que o produto é seguro do ponto de vista higiênico-sanitário e pode ser considerado como potencialmente funcional devido à adequada viabilidade da cultura probiótica.

\section{Agradecimentos}

A equipe gostaria de agradecer à Fundação de Amparo à Pesquisa do Estado de São Paulo, pelo apoio financeiro que viabilizou a execução desta pesquisa; igualmente, às empresas que doaram edulcorante, aromatizantes e corantes; e, em especial, à Profa. Dra. Maricê N. Oliveira pelas valiosas sugestões ao trabalho.

\section{Referências bibliográficas}

1. Antunes, A. E. C.; CAZETTO, T. F.; CARDELlO, H. M. A. B. Iogurtes desnatados probióticos adicionados de concentrado protéico do soro de leite: perfil de textura, sinérese e análise sensorial. Alimentos e Nutrição, v. 15, n. 2, p. 105-114, 2004.

2. AntunES, A. E. C.; CAZETTO, T. F.; BOLINI, H. M. A. Viability of probiotic micro-organism during storage, postacidification and sensory analysis of fat-free yogurts with added whey protein concentrate. International Journal of Dairy Technology, v. 58, n. 3, p.169-173, aug. ,2005.

3. ANTUNES, A. E. C. et al. Selective enumeration and viability of Bifidobacterium animalis subsp. lactis in a new fermented milk product. Brazilian Journal of Microbiology, v. 38, n. 1, p. 173-177, jan./mar., 2007.

4. ANTUNES, A. E. C. et al. Parâmetros físicos e microbiológicos de leite fermentado probiótico tipo buttermilk. In: Simpósio Brasileiro sobre Desenvolvimento de Novos Produtos Alimentícios, Campinas, 08-09 maio 2006.

5. BARRETO, G. P. M. et al. Quantificação de Lactobacillus acidophilus, bifidobactérias e bactérias láticas totais em produtos probióticos comercializados no Brasil. Brazilian Journal of Food Technology, v. 6, n. 120, p. 119-126, 2003.

6. BOTELHO, L. Isolamento e identificação de Lactobacilos e Bifidobactérias em alimentos probióticos disponíveis no mercado brasileiro. Campinas, 2005, 203 p. Tese (Doutorado em Tecnologia de Alimentos), Faculdade de Engenharia de Alimentos, Universidade Estadual de Campinas (UNICAMP), 2005.

7. BRASIL, 2000. Ministério da Agricultura e do Abastecimento. Secretaria de Defesa Agropecuária. Departamento de Inspeção de Produtos de Origem Animal. Resolução $\mathbf{n}^{\circ} 5$, de 13 de novembro de 2000. Disponível em: < http://oc4j.agricultura.gov.br/agrolegis/ do/consultaLei> Acesso em: 10 fev. 2006.

8. BROLAZO, E. M. Seleção e utilização de bactérias lácticas produtoras de diacetil em leites fermentados. 2003, $98 \mathrm{f}$.. Dissertação (Mestrado em Biologia) - Faculdade de Biologia, Universidade Estadual de Campinas, 2003. 
9. GROSSO, C. R. F.; FÁVARO-TRINDADE, C. S. Stability of free and immobilized Lactobacillus acidophilus and Bifidobacterium lactis in acidified milk and immobilized B. lactis in yoghurt. Brazilian Journal of Microbiology, v. 35, n. 1-2, p. 151-156, jan.jjun., 2004.

10. GILlILAND, S. E.; REILLY, S. S.; KIM, H. S. Viability during storage of selected probiotic lactobacilli and bifidobacteria in yogurt-like product. Food Microbiology and Safety, v. 67, n. 8, p. 3091-3095, oct., 2002.

11. HASCHKE, F. et al. Clinical trials prove the safety and efficacy of the probiotic strain Bifidobacterium Bb12 in follow-up formula and growing-up milks. Monatsschr Kinderheikd, v. 146, p. 26-30, 1998. Suplemento.

12. HEILER, C.; SCHIEBERLE, P. Model studies on the precursors and formation of the metallic smelling $(E, Z)-2,6$-nonadienol during the manufacture and storage of buttermilk. International Dairy Journal, v. 7, n. 10, p. 667-674, oct., 1997.

13. HELLER, K. J. Probiotic bacteria in fermented foods: product characteristics and starter organisms. The American Journal of Clinical Nutrition, v. 73, n. 2, p. 374s-379s, feb., 2001.

14. LERAYER, A. L. S.; BROLAZO, E.; TALEB, O. Buttermilk: uma alternativa para o setor de leites fermentados e bebidas láticas. Indústria de Laticínios, jan-fev, p. 50-53, 2001.

15. MASCO, L. et al. Culture-dependent and culture independent qualitative analysis of probiotic products claimed to contain bifidobacteria. International Journal of Food Microbiology, v. 102, n. 2, p. 221-130, jul., 2005.

16. MÖLLER, C.; DE VERSE, M. Review: probiotic effects of selected acid bacteria. Milchwissenschaft, v. 59, n. 11-12, p. 597-600, 2004.

17. NAIDU, A. S., BIDLACK, W. R., CLEMENS, R. A. Probiotic spectra of lactic acid bacteria (LAB). Critical Review in Food Science and Nutrition, v. 38, n. 1, p. 13-126, jan., 1999.
18. O'CONNELL, J. E.; FOX, P. F. Heat stability of buttermilk. Journal of Dairy Science, v. 83, n. 8, p. 1728-1732, 2000.

19. RODAS, B. A. et al. Preparation of probiotic buttermilk with Lactobacillus reuteri. Milchwissenschaft, v. 57, n. 11, p.26-28, 2002.

20. SAXELIN, M.; KORPELA, R.; MAYARA-MAKINEN, A. Introduction: classifying functional dairy products. In: MATTILA-SANDHOLM, T.; SAARELA, M. (Eds), Functional Dairy Products. New York, Boca Raton, 2003.

21. SAMONA, R.; ROBINSON, R. K. Enumeration of bifidobacteria in dairy products. Journal of the Society of Dairy Technology, v. 44 , n. 3, p. 64-66, 1991.

22. SILVA, N.; JUNQUEIRA, V. C. A.; SILVEIRA, N. F. A. Manual de Métodos de Análise Microbiológica de Alimentos. São Paulo: Varela, 2001. 317p.

23. TAMIME, A. Y.; MARSHALL, V.; ROBINSON, R. Microbial and technological aspects of milks fermented by bifidobacteria. Journal of Dairy Research, v. 62, n. 1, p. 151-187, 1995.

24. TEMMERMAN, R. et al. Culture-independent analysis of probiotic products by denaturing gradient gel electrophoresis. Applied and Environmental Microbiology, v. 69, n. 1, p. 220-226, feb., 2003.

25. TRINDADE, M. I.; ABRATT, V. R.; REID, S. J. Induction of sucrose utilisation genes from Bifidobacterium lactis by sucrose and raffinose. Applied and Environmental Microbiology, v. 69, n. 1, p. 24-32, jan., 2003.

26. VINDEROLA, C. G. et al. Influence of compounds associated with fermented dairy products on the growth of lactic acid starters and probiotic bacteria. International Dairy Journal, v. 12, n. 7, p. 579-589, 2002.

27. VOGENSEN, F. K. et al. Improved direct differentiation between Leuconostoc cremoris, Streptococcus lactis subsp. diacetylactis, and Streptococcus cremoris/Streptococcus lactis on agar. Milchwissenschaft, v. 42, n. 10, p. 646-648, 1987. 